\title{
Biokimia Mycobacterium Tuberculosis yang Diberi Perlakuan Obat Anti TB Isoniazid
}

\section{Biochemistry Mycobacterium Tuberculosis Treated with Anti-Isoniazid Treatment}

\author{
ELLY KARLINA* \\ WIDODO** \\ DEVI ETIVIA PURLINDA**
}

\author{
Balai Laboratorium Kesehatan \& Pengujian Alat Kesehatan Provinsi Jawa Tengah* \\ Jl. Soekarno Hatta No.185, Palebon, Kec. Pedurungan, Kota Semarang \\ Jurusan Analis Kesehatan Poltekkes Kemenkes Semarang** \\ Jl. Wolter Monginsidi Pedurungan Tengah, Kota Semarang \\ Email:widodosst125@gmail.com
}

\begin{abstract}
Abstrak
Mycobacterium tuberculosis yang terpapar Isoniazid ada kemungkinan terjadi ketahanan terhadap obat tersebut karena faktor morfologi dan seleksi, dengan konsentrasi Isoniazid 0,5 $\mu \mathrm{g} / \mathrm{ml}$ dengan lama waktu paparan 24, 48, 72 dan 96 jam diperoleh hasil uji ketahana terhadap $\mathrm{NaCl} 5 \%$ Kruskal wallis untuk uji ketahanan terhadap $\mathrm{NaCl} 5 \%$ diperoleh hasil sig 0,005 ada pengaruh perlakukan terhadap pertumbuhan. Sedangkan pada uji katalase semi kuantitatif diperoleh nilai sig 0,007 dengan $p<0,01$ kesimpulan ada pengaruh yang signifikan antara lama paparan Isoniazid. resistensi terjadi dikarenakan adanya proses seleksi terhadap strain yang tahan terhadap perlakuan selama proses terapi. resistensi hanya pada paparan yang terlama yaitu 96 jam dengan persentase $2 \%$. Pada proses pemaparan dapat disimpulkan bahwa akan merubah ketahanan terhadap $\mathrm{NaCl} 5 \%$, perubahan hasil uji Katalase dan menyebabkan juga seleksi strain yang tahan terhadap ISONIAZID $0,5 \mu \mathrm{g} / \mathrm{ml}$.
\end{abstract}

Kata Kunci: Mycobacterium tuberculosis ; Isoniazid ; Biokimia

\begin{abstract}
Mycobacterium tuberculosis exposed to Isoniazid experienced drug resistance due to morphological and selection factors, with Isoniazid concentrations of $0.5 \mu \mathrm{g} / \mathrm{ml}$ with a contact time of 24 hours, 48 hours, 72 hours, 96 hours, the results obtained in testing for $\mathrm{NaCl} 5 \%$ Kruskal wallis obtained sig 0.005 results there is a treatment effect on growth While in the semi-quantitative catalase test, a sig value of 0.007 was obtained with $p<0.01$ so it can be concluded that there is a significant influence between the duration of isoniazid exposure. resistance occurs due to the selection of strains that are resistant to treatment during the therapy process at 96 hours exposure with a percentage of $2 \%$. In the exposure process it can be concluded that it will change the resistance to $5 \% \mathrm{NaCl}$, changes in Catalase test results and also causes strain selection that is resistant to isoniazid $0.5 \mu \mathrm{g} / \mathrm{ml}$.
\end{abstract}

Keyword: Mycobacterium tuberculosis ; Isoniazid ; Biochemistry

\section{Pendahuluan}

Setelah ditemukannya obat anti tuberkulosis seperti Streptomisin (STR), para asam amino salisilat (PAS) dan asam Isoniazid (isonicotinic acid hydrazide/ isoniazid), munculnya kasus strain bakteri resisten yang diamati pada isolat klinis Mycobacterium tuberculosis (Crofton dan Mitchison, 1948). Mycobacterium tuberculosis yang resisten terhadap obat telah dilaporkan sejak masa awal pengenalan kemoterapi, namun sebagian besar bukti itu 
terbatas pada negara-negara maju isoniazid aktif terhadap basil Mycobacterium tuberculosis yang melakukan replikasi atau tumbuh dengan metabolisme aktif yang dikenal sebagai asam isonikotinat hidroksida menurut Zhang et al (2009) menyatakan bahwa resistensi Mycobacterium tuberculosis terhadap isoniazid dengan frekuensi 1 sel dari $10^{5}-10^{6}$ basil per generasi. Sedangkan Kochi et al (1993) menyatakan bahwa resistensi Mycobacterium tuberculosis terjadi karena seleksi strain yang terjadi pada proses terapi selain itu juga mutasi spontan pada gen kromosom. Yang akan dibuktikan pada penelitian ini apakah dari sampel dahak pasien TBC yang belum mendapatkan pengobatan akan terjadi resistensi bila diberi perlakukan obat TB Isoniazid.

\section{Metode}

Bakteri Mycobacterium tuberculosis dari kultur Lowenstein Jensen dibuat suspensi yang setara dengan standar $1 \mathrm{McFarland}, 10^{8} \mathrm{CFU} / \mathrm{ml}$, kemudian dilakukan paparan dengan isoniazid $0,5 \mu \mathrm{g} / \mathrm{ml}$ pada media cair Middlebrook 7H9, lama waktu paparan 24 jam untuk sampel X1, 48 jam untuk sampel X2, 72 jam untuk sampel X3 dan 96 jam untuk sampel X4. Kemudian dipipet sebanyak $100 \mu 1$ dimasukan pada Lowenstein Jensen dengan kadar $\mathrm{NaCl}$ $5 \%$, diinkubasi pada suhu $35{ }^{\circ} \mathrm{C}$ diamati tiap minggu selama 4 minggu bila terdapat lebih dari 50 koloni dikatakan positif kurang dari 50 koloni negatif (Conville dan Witebsky, 1998).

Uji katalase semi kuantitatif menggunakan campuran hidrogen peroksida $15 \%$ dan Tween 80 konsentrasi 10\% dengan perbandingan 2:1 ditambahkan dengan koloni Mycobacterium tuberculosis dari medium Lowenstein Jensen setelah di inkubasi selama 2 minggu. H37Rv sebagai kontrol positif uji catalase (Zhang et al., 1993). Hasil positif terbentuk gelembung gas hasil negatif tidak terbentuk gelembung gas setelah di inkubasi pada suhu kamar selama 5 menit tinggi gelembung gas yang terbentuk di ukur dalam milimeter (modifikasi dari Ramaswamy et al., 2003)

\section{Hasil dan Pembahasan}

\section{A. Kultur dan uji subtype Mycobacterium tuberculosis}

Hasil kultur dibuat suspensi sesuai standar kekeruhan $1 \mathrm{McFarland} 10^{8} \mathrm{CFU} / \mathrm{ml}$, kemudian dilakukan paparan dengan isoniazid $0,5 \mu \mathrm{g} / \mathrm{ml}$ pada media cair Middlebrook $7 \mathrm{H} 9$, lama waktu paparan 24 jam untuk sampel X1, 48 jam untuk sampel X2, 72 jam untuk sampel X3 dan 96 jam untuk sampel X4.

Tabel 1. Tabel kultur dan uji subtipe Mycobacterium tuberculosis

\begin{tabular}{ccccccc}
\hline No & $\begin{array}{c}\text { Kode } \\
\text { Sampel }\end{array}$ & $\begin{array}{c}\text { Hasil } \\
\text { Kultur }\end{array}$ & PNB & Niacin & $\begin{array}{c}\text { Katalase } \\
\text { Panas }\end{array}$ & $\begin{array}{c}\text { Uji DST } \\
\text { ISONIAZID }\end{array}$ \\
\hline 1 & X1 & $3+$ & - & + & - & $\mathrm{S}$ \\
2 & $\mathrm{X} 2$ & $3+$ & - & + & - & $\mathrm{S}$ \\
3 & $\mathrm{X} 3$ & $3+$ & - & + & - & $\mathrm{S}$ \\
4 & $\mathrm{X} 4$ & $3+$ & - & + & - & $\mathrm{S}$ \\
\hline & : Negatif & & $\mathrm{S}$ & : Sensitif & & \\
+ & : Positif & & &
\end{tabular}

Bakteri non asam dengan pertumbuhan cepat yang menunjukan adanya kontaminasi sebagaimana dinyatakan oleh Boum et al. (2013) 


\section{B. Ketahanan $\mathrm{NaCl} 5 \%$ dan Uji katalase}

Inokulum $1 \mathrm{Mc}$ Farland sebanyak $100 \mu \mathrm{l}$ ditanam pada media LJ dengan konsentrasi $\mathrm{NaCl} 5 \%$, di inkubasi pada suhu $35^{\circ} \mathrm{C}$ selama 4 minggu pada tiap minggu dilakukan pengamatan, pertumbuhan koloni dengan syarat lebih dari 50 koloni dinyatakan positif kurang dari 50 koloni dinyatakan negatif (Conville dan Witebsky, 1998).

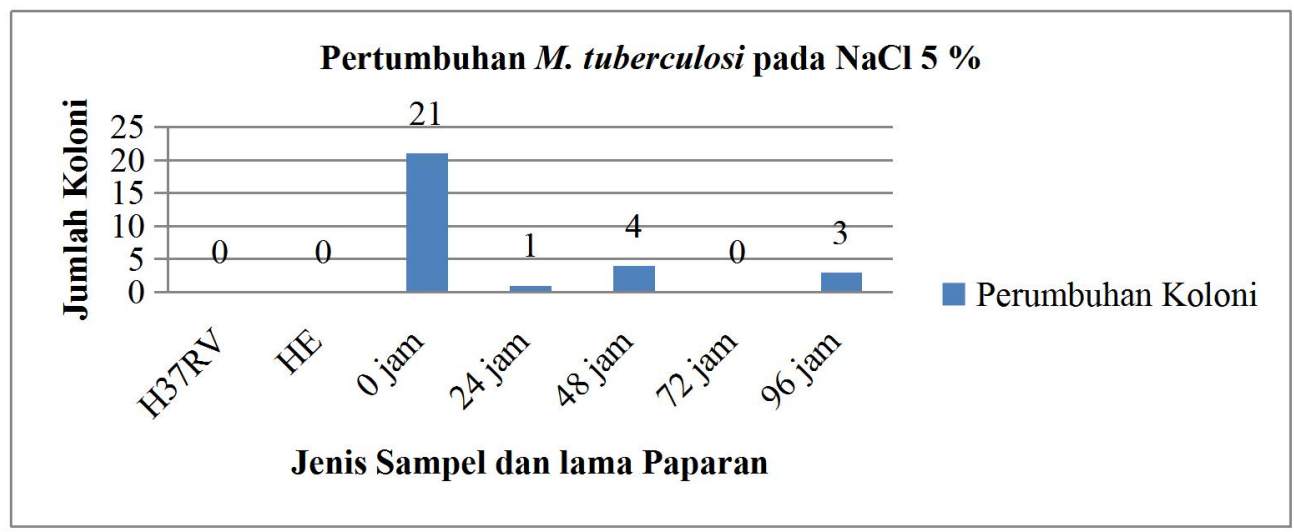

Gambar 1. Pertumbuhan sel Mycobacterium tuberculosis pada $\mathrm{NaCl} 5 \%$

Hasil uji ketahanan Mycobacterium tuberculosis dapat diamati pada gambar 4.4 bahwa sel yang tidak terpapar memiliki pertumbuhan yang sangat tinggi sebanyak 21 koloni, pada saat dipaparkan dengan isoniazid $0,5 \mu \mathrm{g} / \mathrm{ml}$ selama 24 jam tumbuh 1 koloni, pada paparan 48 jam tumbuh 4 koloni, pada 72 jam tidak ada koloni yang tumbuh dan pada 96 jam mulai terlihat kembali pening katan jumlah pertumbuhan. Hasil uji dilakukan pengulangan diperoleh pola yang sama.

Pengelompokan toleransi terhadap garam dikelompokkan menjadi 3 yaitu 1) sensitif garam dengan pertumbuhan pada konsentrasi garam $\leq 3 \%$ diantaranya Mycobacterium tuberculosis complex, Mycobacterium chelonae, Mycobacterium centiflacum. 2) intermediate pertumbuhan pada konsentrasi garam 4-6\% terdiri Mycobacterium avium, Mycobacterium intracellulare. 3) resisten mampu tumbuh pada konsentrasi garam $>6 \%$ yang terdiri dari Mycobacterium homonissuis, Mycobacterium boletti (Asmar et al., 2016).

M. Tuberculosis sebagai kontrol positif (HE) dan kontrol negatif (H37Rv) tidak tumbuhan pada medium $\mathrm{NaCl} 5 \%$. Sedangkan pada sampel uji yang diperoleh dari dahak mampu tumbuh pada $\mathrm{NaCl} 5 \%$. Mycobacterium tuberculosis dari dahak manusia mengalami proses adaptasi dengan $\mathrm{NaCl}$ secara alami $50 \mathrm{mM}$ di permukaan saluran pernapasan dan 250 $\mathrm{mM}$ di permukaan cairan dalam makrofag karena proses ini cenderung memiliki efek yang signifikan terhadap permeabilitas dan fluiditas membrane, yang melindungi sel terhadap peningkatan salinitas dan tekanan osmotic (Larrouy et al., 2016).

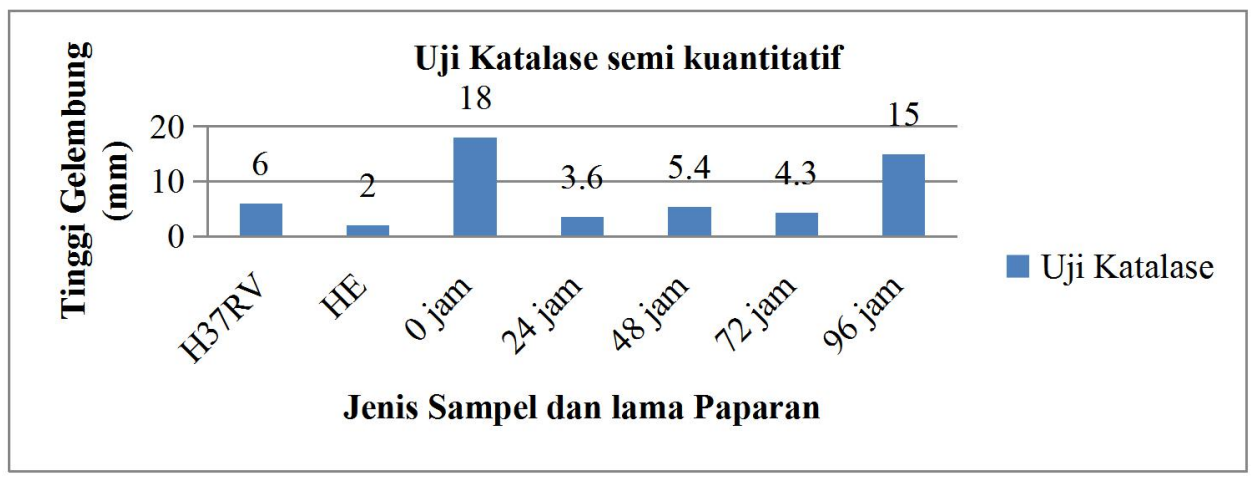

Gambar 2 Hasil katalase semi kuantitatif 
Aktivitas katalase pada $68{ }^{\circ} \mathrm{C}$ dievaluasi untuk membedakan Mycobacterium tuberculosis kompleks dengan bakteri lainya. Tes semi kuantitatif dilakukan dengan menambahkan superoxol ke dalam kultur Mycobacterium tuberculosis yang tumbuh 2 minggu dengan Lowenstein Jensen tegak pada $37{ }^{\circ} \mathrm{C}$. kekuatan reaksi katalase di dalam tabung jika ketinggian gelembung $>45 \mathrm{~mm}$ dinyatakan positif terdiri dari Mycobacterium kansasii, Mycobacterium simiae, bila $<45 \mathrm{~mm}$ dinyatakan negatif terdiri dari Mycobacterium tuberculosis, Mycobacterium marinum, Mycobacterium avium complex, Mycobacterium xenopi dan Mycobacterium gastri (Babady dan Wengenack, 2012).

Pada uji statistik non - para metrik Kruskal wallis untuk uji ketahanan terhadap $\mathrm{NaCl}$ $5 \%$ diperoleh hasil sig 0,005 dengan $\mathrm{p}<0,01$ sehingga dapat disimpulkan ada pengaruh yang signifikan antara lama paparan dengan pertumbuhan Mycobacterium tuberculosis pada media $\mathrm{NaCl} 5 \%$. Sedangkan pada uji katalase semi kuantitatif diperoleh nilai sig 0,007 dengan $\mathrm{p}<0,01$ sehingga dapat disimpulkan ada pengaruh yang signifikan antara lama paparan isoniazid dengan tingginya gelembung gas dalam $(\mathrm{mm})$ pada uji katalase semi kuantitatif.

\section{Hasil paparan M. tuberculosis dengan isoniazid $0,5 \mu \mathrm{g} / \mathrm{ml}$ dengan lama paparan 96 jam hasil menujukkan ketahanan terhadap isoniazid.}

Tabel 3 Hasil Uji DST (drung susceptibility test)

\begin{tabular}{|c|c|c|c|c|c|}
\hline & & \multicolumn{4}{|c|}{ Kode sampel } \\
\hline & & X1 (24 jam) & $\mathrm{X} 2$ (48 jam) & X3(72 jam) & $\mathrm{X} 4$ (96 jam) \\
\hline \multirow[t]{2}{*}{ Pengenceran } & TO (D) & ISONIAZID & ISONIAZID & ISONIAZID & ISONIAZID \\
\hline & & 0,2 & 0,2 & 0,2 & 0,2 \\
\hline $1 / 1000$ & 50 & 0 & 0 & 0 & 1 \\
\hline $1 / 100000$ & 4 & 0 & 0 & 0 & 0 \\
\hline persentase & & 0 & 0 & 0 & 2 \\
\hline \multicolumn{6}{|l|}{ Resisten } \\
\hline Hasil & & $\mathrm{S}$ & $\mathrm{S}$ & $\mathrm{S}$ & $\mathbf{R}$ \\
\hline
\end{tabular}

Pada penelitian ini resistensi terjadi dikarenakan adanya proses seleksi terhadap strain yang tahan terhadap perlakuan selama proses terapi. resistensi hanya pada paparan yang terlama yaitu 96 jam dengan persentase $2 \%$ dari $1 \mathrm{McF}$ arland atau $10^{8} \mathrm{CFU} / \mathrm{ml}$. hasil tersebut tidak menujukan adanya resistesi genetic karena yang diuji hanya pertumbuhan Mycobacterium tuberculosis pada media Lowenstein jenzen.

\section{Simpulan dan Saran}

\section{Simpulan}

Pada proses pemaparan akan merubah ketahanan terhadap $\mathrm{NaCl} 5 \%$, perubahan hasil uji Katalase dan menyebabkan juga seleksi strain yang tahan terhadap isoniazid $0,5 \mu \mathrm{g} / \mathrm{ml}$.

\section{Saran}

Pengobatan sangatlah penting bagi Pasien TBC jangan sampai terputus dalam pengobatan akan menyebabkan terjadinya resistensi seperti yang di perlihatkan dalam penelitian ini 


\section{Daftar Pustaka}

Asmar, S., Sassi, M., Phelippeau, M., and Drancourt, M. 2016. Inverse correlation between salt tolerance and host-adaptation in mycobacteria. BMC research notes, 9(1), 1-9. https://doi.org/10.1186/s13104-016-2054-y

Babady, N. E., and Wengenack, N. L. 2012. Clinical laboratory diagnostics for Mycobacterium tuberculosis, understanding tuberculosis-global experiences and innovative approaches to the diagnosis. ISBN, 978-953.

Boum, Y., Orikiriza, P., Rojas-Ponce, G., Riera-Montes, M., Atwine, D., Nansumba, M., Bazira, J., Tuyakira,E., De Beaudrap, P., Bonnet, M., and Page, A. L. 2013. Use of colorimetric culture methods for detection of Mycobacterium tuberculosis complex isolates from sputum samples in resource-limited settings. Journal of Clinical Microbiology 51(7): 2273-2279. DOI: 10.1128/JCM.00749-13

Conville, P. S., and Witebsky, F.G. 1998. Variables affecting results of sodium chloride tolerance test for identification of rapidly growing mycobacteria. Journal of Clinical Microbiology 36.6 : 1555-1559. DOI: 10.1128/JCM.36.6.1555-1559.1998

Crofton, John, and D. A. Mitchison. 1948. Streptomycin resistence in pulmonary tuberculosis. British Medical Journal 2.4588 : 1009. doi: 10.1136/bmj.2.4588.1009

Kochi, A., Vareldzis, B., and Styblo, K. 1993. Multidrug-resisten tuberculosis and its control. Research in microbiology, 144(2): 104-110. https://doi.org/10.1016/0923-2508(93)90023-U

Larrouy-Maumus, G., Marino, L. B., Madduri, A. V., Ragan, T. J., Hunt, D. M., Bassano, L., Gutierrez, M.G., Moody, D.B., Pavan, F. R., and de Carvalho, L. P. S. 2016. Cell-Envelope Remodeling as a Determinant of Phenotypic Antibacterial Tolerance in Mycobacterium tuberculosis. ACS Infectious Diseases 2(5): 352-360. doi.org/10.1021/acsinfecdis.5b00148

Ramaswamy, S. V., Reich, R., Dou, S. J., Jasperse, L., Pan, X., Wanger, A., Quitugua, T., and Graviss,A, 2003. Single nucleotide polymorphisms in genes associated with Isoniazid resistence in Mycobacterium tuberculosis. Antimicrobial Agents and Chemotherapy, 47 : 1241-1250. doi.org/10.1021/acsinfecdis.5b00148

Widodo, W., Irianto, A., dan Pramono, H. 2017. Karakteristik Morfologi Mycobacterium tuberculosis yang Terpapar Obat Anti TB Isoniazid (INH) secara Morfologi. Majalah Ilmiah Biologi BIOSFERA: A Scientific Journal, 33(3), 109-115. Doi 10.20884/1.mib.2016.33.3.316

Zhang, Y., Garbe, T., and Young, D. 1993. Transformation with Kat G restores Isoniazid-sensitivity in Mycobacterium tuberculosis isolates resisten to a range of drug concentrations. Molecular Microbiology, 8(3): 521-524. doi.org/10.1111/j.1365-2958.1993.tb01596.x

Zhang, Y., Heym, B., Allen, B., Young, D., and Cole, S. 1992. The catalase-peroxidase gene and Isoniazid resistence of Mycobacterium tuberculosis, Nature, 358 (6387), 591 - 593. doi.org/10.1038/358591a0

Zhang, Y., and Yew, W. W. 2009. Mechanisms of drug resistence in Mycobacterium tuberculosis [State of the art series. Drug-resisten tuberculosis. Edited by CY. Chiang. Number 1 in the series]. The International Journal of Tuberculosis and Lung Disease, 13(11): 1320-1330. 